\title{
Historical church diagnostic with regards to impact of traffic included vibrations
}

\author{
Krzysztof Koziol $^{1, *}$ \\ ${ }^{1}$ Cracow University of Technology, Institute of Structural Mechanics, 31-155 Kraków, Warszawska \\ 24 St., Poland
}

\begin{abstract}
In the article problem of a comprehensive diagnosis of a historic building with damages is discussed. Dynamic investigations carried out in the church of St. Nicholas in the center of Krakow are an example of diagnostic tests provided to determine the causes of damage. Because the tested structure is exposed to traffic vibrations caused by wheeled vehicles and train passes, special attention has been paid to the impact of these vibrations onto a historic object. Results of measurements of these vibrations as well as dynamic analyzes obtained using FEM model of the investigated church were given.
\end{abstract}

\section{Introduction}

A long with the development of road infrastructure, the sources of transport vibrations are brought closer to the existing buildings including historical objects. Diagnostics of the technical condition of these objects cannot ignore the influence of vibrations generated during the passage of vehicles. Appropriate diagnostic analyzes should be carried out taking into account not only the current impact on the building but also occurring in the past. Dynamic diagnosis regarding the historical church in Krakow [1] may be a good example confirming the above statement. It is therefore worth disseminating the procedure used to develop this diagnosis.

\section{Characteristics of the object and the purpose of the diagnosis}

Church of St. Nicholas is located in the central part of Krakow. Near the church, from the eastern side, there are located train tracks on the embankment and on the north side - a street on which cars move (see Figure 1).

This church is one of the oldest historic buildings in Krakow. It is under heritage protection. The origins of the building date back to the 12th century. It is not a homogeneous object - it has been rebuilt and expanded several times. In its present architectural form it is a threenave, Baroque and neo-Baroque basilica. However, Romanesque and Gothic relicts can be found in the walls of the temple.

*Corresponding author: kkoziol@pk.edu.pl 
At the end of the 60 s of the last century there has been a marked increase in the intensity of movement of trains on tracks located in the vicinity of the church. Dynamic measurements were made (see [2]) and after a detailed analysis it was proposed to use the bulkhead construction (vibroinsulating barrier) in the ground to a depth of $3.0 \mathrm{~m}$ as a technical way to reduce vibrations generated and transferred through the ground to the church during train passages. Subsequent decisions that reduced the intensity of railway traffic and redirected freight trains to different line, bypassing the Krakow Main Station, caused the withdrawal of the railway line user from the implementation of the vibroinsulating barrier in the ground.

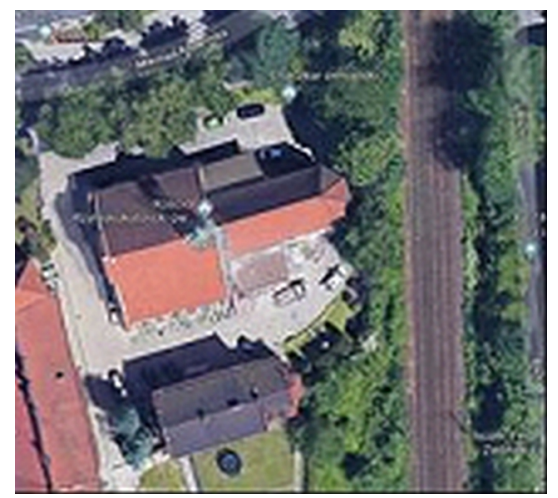

Fig. 1. Location of the analyzed object with vibration sources.

In the 70's and 90's of the last century reconstruction of the gable wall from the west side and reinforcement and renovation of the church roof were made. Currently, numerous damages in the form of scratches and cracks can be found on the church walls and vaults. Before commencing renovation works it was necessary to determine the causes of these damages and to give conclusions and recommendations regarding the repair and protection of the church.

\section{The scope of carried out diagnostic investigations}

A comprehensive analysis of the dynamic response of the church structure contained:

- inventory, analysis and evaluation of structural damage,

- vibration measurements at selected points generated during the passage of trains and cars,

- computer analysis of the structure resistance to paraseismic effects caused by the passage of trains and cars,

- outcrops in the ground between the east wall and the base of the railway embankment in order to check the existence of anti-shock protection along the railway track and evaluate its technical condition,

- complete geotechnical documentation of the ground below analyzed object,

- outcrops and checking the technical condition of rainwater drainage installations.

On this basis and taking into account information contained in [3] following was developed:

- guidelines and recommendations for the construction-executive project of reinforcing the ground under the foundations, 
- guidelines and recommendations for the construction-executive project of necessary repairs and strengthening the structural elements of the historic church,

- guidelines and recommendations for the scope and range of execution of anti-shock protection under railway tracks related to the planned reconstruction and modernization of tracks.

\section{Description of the damages}

The analysis of cracks on the surfaces of the walls is usually the most reliable source of information to establish the mechanisms and causes of the damage. On the basis of a detailed inventory of scratches and cracks in the walls of the church structure it was found that they are cross-cut, i.e. they pass through the entire thickness of the walls. In the case of the vaults, identification of the cracks' progress into the structure was not possible due to the lack of direct access. It seems that the location of some cracks in the vaults may indicate their cross-nature, which results in the loss of cooperation between the fragments of the vault separated by such a crack.

On the transverse walls in the southern side nave there are scratches in the vicinity of external buttresses. The nature of these scratches is directly related to the lack of bonds between the transverse walls and the original external church buttresses built in the early twentieth century. The existing cracks reflect the original ledges and faults located on the outer edge of the scarps.

The largest scale of splits and cracks occurs in the south-western corner of the church. Therefore, it was analyzed whether the substructure was loosen under this part of the structure. It turned out that archaeological excavations were performed here in the past. However, no documentation regarding these works has been preserved. Therefore, it is not possible to state clearly what was the depth of excavations and size of the works carried out there. The unknown historical wall discovered then in this region may indicate a wide variety of foundation conditions. It is also known that in the area of the described corner of the church there is a connection to the drainage system of the drainage pipe of the roof. Periodic leaks of rainwater to the ground may cause it to loose as a result of washing away silty parts. Despite significant extent and gap between the cracks at this corner of the church, cracks distribution on the north facade does not confirm the uneven foundations settlement as the dominant cause of damage. Possible settlement could only deepen the scale of damage.

The soil substrate was also tested at the location of the church. On this basis geotechnical conditions of foundation below the church were considered favorable. A review and monitoring of the entire storm sewer system was also carried out. The review concerned gullies inlets starting from inspection grates to collector wells and channels between wells. After checking over 31 linear meters of the installation and carrying out flow tests, investigated installation was confirmed to be unobstructed. However, it was found that the installation is in poor technical condition and needs renovation particularly detected cracks should be repaired.

\section{Investigation and evaluation of the influence of communication sources of vibrations onto church structure}

Vibration were measured at selected points located on the church structure. These vibrations were generated by passing trains along the Krakow-Medyka route no. 91 and by cars passing along Kopernika st. Acceleration of vibrations components were measured in three directions: two horizontal " $x$ " (along the longitudinal axis of the church - 
perpendicular to the track line) and " $y$ " (perpendicular to the longitudinal axis of the church - parallel to the track line) and one vertical direction " $z$ ". Measurements were made at three measuring points on the structure at ground level (on the foundation) and respectively at three points at the level of the wall top.

Below are presented maximum values of vibration acceleration recorded during the passage of trains:

- at the ground level (foundation): component " $x "-1,25 \mathrm{~cm} / \mathrm{s}^{2}$, component " $y$ " $2,12 \mathrm{~cm} / \mathrm{s}^{2}$ (vibro-acceleration shown on fig.2) component " $\mathrm{z}$ " - $1,34 \mathrm{~cm} / \mathrm{s}^{2}$,

- at the level of the wall's top: component " $x$ " - 4,64cm/s $/ \mathrm{s}^{2}$, component " $y$ " the cars: $7,73 \mathrm{~cm} / \mathrm{s}^{2}$, component “z”- $4,72 \mathrm{~cm} / \mathrm{s}^{2}$.

- at the ground level (foundation): component " $x$ " - 0,22 cm/s $\mathrm{s}^{2}$, component " $y$ " $0,28 \mathrm{~cm} / \mathrm{s}^{2}$, component " $\mathrm{z}$ " $-0,32 \mathrm{~cm} / \mathrm{s}^{2}$,

- at the level of the wall's top: component " $x$ " $-1,12 \mathrm{~cm} / \mathrm{s}^{2}$, component " $\mathrm{y}$ " - 1,33 $\mathrm{cm} / \mathrm{s}^{2}$, component " $\mathrm{z}$ " $-0,77 \mathrm{~cm} / \mathrm{s}^{2}$.
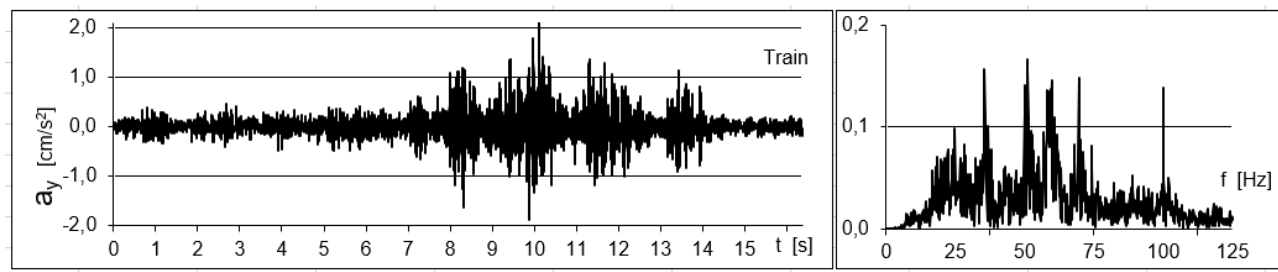

Fig. 2. Vibro-acceleration (and its frequency spectrum) of foundation in the direction of $y$.

The level of vibrations caused by passing cars along Kopernika st. was several times smaller than the values given above.

Recorded vibrations waveform were used to carry out analysis allowing assessment of the influence of vibrations of communication origin onto the church structure. For this purpose a 3D FEM model of the structure was prepared. Fig. 3 shows the applied division of the structure into finite elements.
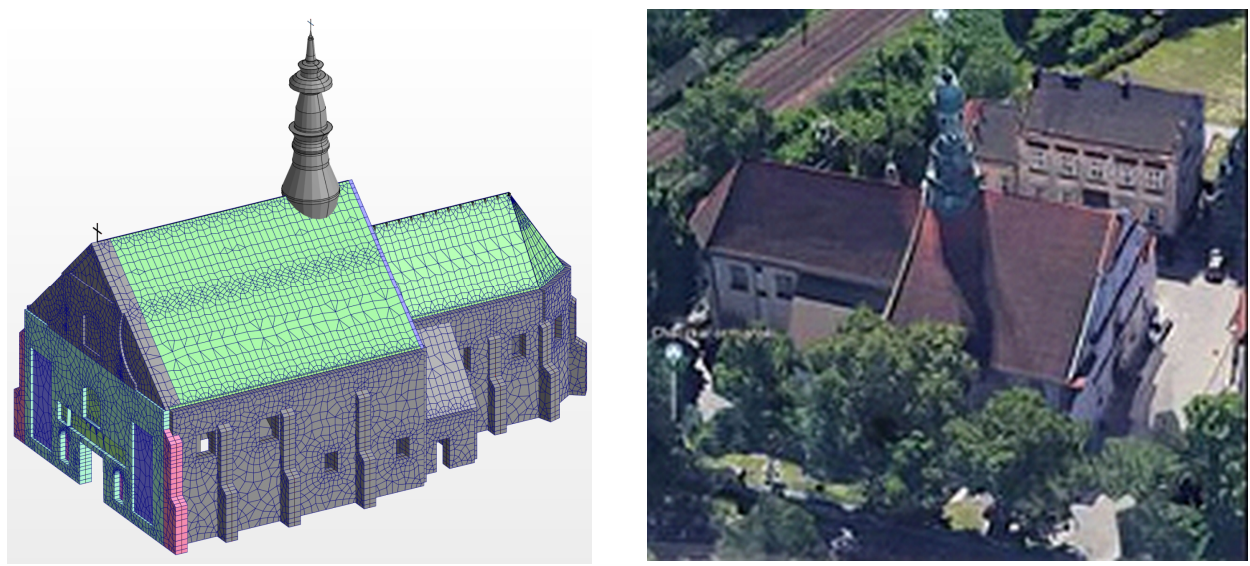

Fig. 3. Division of the computational model into finite elements and photo google maps.

Dimensions and distribution of finite elements were adopted in accordance with the available documentation, including its verification during the damage inventory. Applied calculation model also takes into account the larger damage occurring in the construction, 
assuming appropriate density of the element mesh in the vicinity of these locations (see Fig. 4).

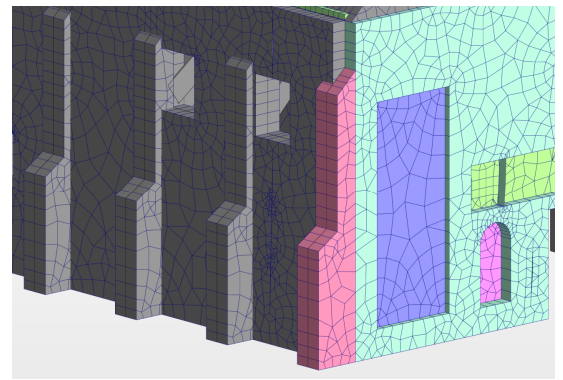

Fig. 4. Part of a FEM model with enlarged mesh density around visible damages.

During FEM model preparation, it was assumed that the materials present in the structure are characterized by the following values:

- brick wall: Young's modulus $\mathrm{E}=3,2 \mathrm{GPa}$; Poisson's ratio $\mathrm{v}=0,2$; mass density $\rho=2000 \mathrm{~kg} / \mathrm{m} 3$, material is present in the walls and foundations;

- pine wood: Young's modulus $\mathrm{E}=6,0 \mathrm{GPa}$, shear modulus $\mathrm{G}=0,50 \mathrm{GPa}$, mass density $\rho=850 \mathrm{~kg} / \mathrm{m} 3$, material is present in the roof structure.

From recorded measurements of church vibrations for further analysis measurements were chosen as containing the most unfavorable values. Vibrograms registered directly on the foundation of the church were established as a kinematic excitation used in the computational model. It was assumed that this excitation occurs at each node at the interface of the foundation with the ground. The level of the wall's top was taken as the reference. Therefore, the acceleration obtained from the numerical model in the level of the wall's top was compared with the vibration measurements registered during the same measurements. Sufficient results were obtained.

The subject of further analysis was the usage of the FEM model to check if there is a cause-and-effect relationship between the excitation generated by the train passage and the cracks onto object. The tensile stresses occurring in the object were analyzed: in the theoretical cross sections not scratched and real cross sections cracked. An exemplary map of stresses occurring on the south and west facades is shown in Fig. 5a, 5b.

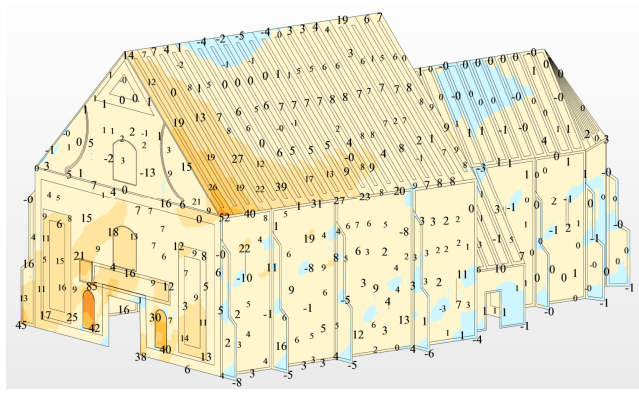

Fig. 5a. An exemplary map of the maximum main stresses (values in $\mathrm{Pa}$, should be treated as variable sign) - caused by vibrations generated by train passage.

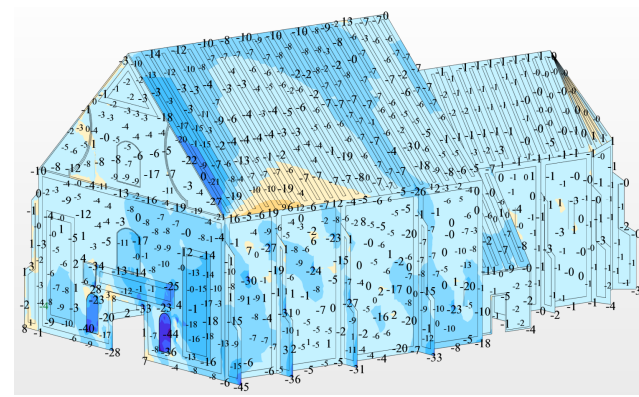

Fig. 5b. An exemplary map of the maximum main stresses (values in $\mathrm{Pa}$, should be treated as variable sign) - caused by vibrations generated by car. 
Basing on the calculations, it was found that the analyzed dynamic action induces tensile stresses with the following values: in the vaults they did not exceed $22 \mathrm{~Pa}$, in longitudinal walls (sideways, perpendicular to the railway track) they reached $45 \mathrm{~Pa}$ and in the presbytery and in the front wall they did not exceed $43 \mathrm{~Pa}$, with the exception of the window opening in the front wall, where they reached the value of $85 \mathrm{~Pa}$.

The stress values obtained from calculations do not indicate that the vibrations caused by currently occurring trains and cars passes could be primary cause of damage to the structural elements of the church. However, they can lead to the disclosure and development of damage caused earlier by different causes.

\section{Conclusions}

Relatively extensive investigations and analysis have identified condition of the structure and outline a course of action with the technical lead for the repair and strengthening. The group of main recommendations includes:

- indication that there is no need to strengthen the ground under foundations,

- indication - in the current traffic and rails conditions - as the most appropriate solution causing reduction of vibrations transmitted to the structure by applying vibration isolation in the construction of railway tracks, which are passing in the vicinity of the church (within the section about $150 \mathrm{~m}-75 \mathrm{~m}$ north and south from the presbytery of the church),

- the level of stress caused by the loads caused by the passage of trains and cars showed that they do not affect the safety of the structure

- indication of the need to repair damage observed in the walls and provision of the protection works scope.

\section{References}

1. K. Stypuła. (head of the authors' team), Specialist structural expertise with making vibration measurements and dynamic computer analysis as well as geotechnical investigations of the ground foundation of the St. Nicholas church at Kopernika 9 st in Cracow, Cracow University of Technology, Institute of Structural Mechanics, November 2009

2. K. Kozioł, K. Stypuła, Simulation calculations during design of vibration isolation of rail surfaces. Selected applications (in Polish), Land - Air - Water ROUTES, No. 10 (2010)

3. PN-B-02170:2016 Evaluation of the harmfulness of building vibrations due to ground motion (in Polish) 